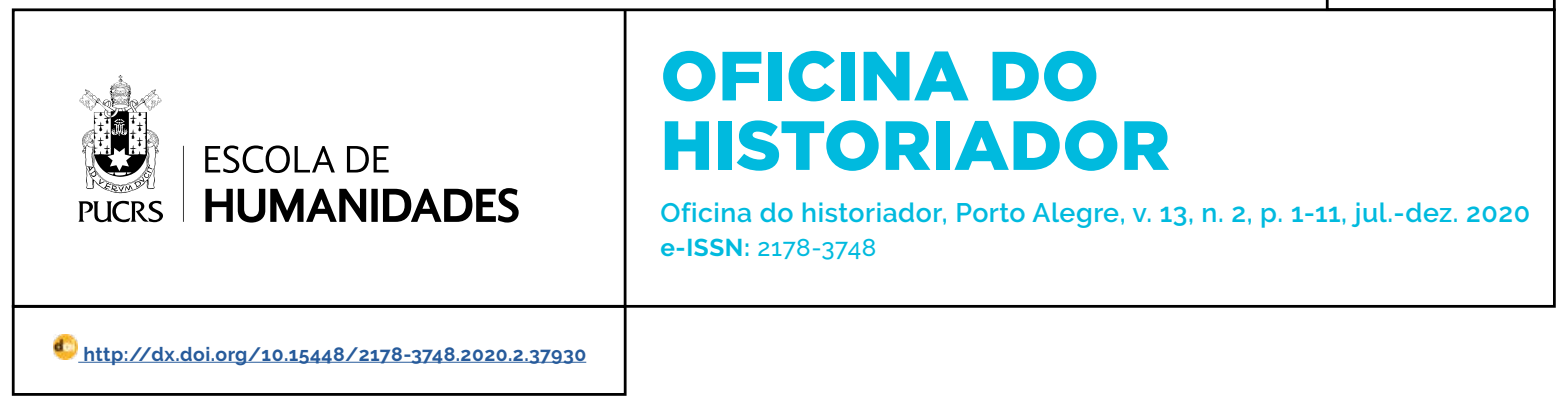

DOSSIÊ

\title{
Os impactos socioambientais e suas ameaças ao modo de vida das comunidades tradicionais de fundo de pasto na Bahia
}

\author{
Socio-environmental impacts and threats to the way of life of traditional grassland \\ communities in Bahia
}

\section{Simone Conceição \\ Soares Dias ${ }^{1}$ \\ orcid.org/0000-0003-3927-5266 \\ simone.monte@hotmail.com}

Recebido em: 30/4/2020.

Aprovado em: 23/7/2020.

Publicado em: 21/12/2020.
Resumo: O presente artigo se propõe a analisar os impactos socioambientais empreendidos por diversos projetos de modernização e de expropriação das terras de uso comum das comunidades tradicionais de fundo de pasto no estado da Bahia. O fundo de pasto, assim autodenominado por seus ocupantes, tem o seu modo de vida pautado no uso comunitário da terra, com a ausência de cercas, para criação extensiva de animais e para o extrativismo de frutas, essas por sua vez, são consumidas e comercializadas por esses moradores. Essas áreas estão localizadas, sobretudo, no bioma caatinga, tendo a sua maior concentração nas regiões Norte e Nordeste da Bahia e, de modo geral, enfrentam diversos problemas referentes à garantia da posse da terra, que remontam à Lei de Terras de 1850 e a diversas legislações posteriores, que não ampararam o seu modo de utilização comunitária da terra. Além da ausência de cercas, também praticam a preservação ambiental, uma vez que não utilizam o desmatamento, nem a caça predatória. A partir da década de 1970, essas comunidades vêm enfrentando uma série de conflitos motivados principalmente, pela incursão da grilagem em suas terras objetivando a concentração fundiária e a implantação de projetos modernizantes, como a construção de grandes barragens, a implantação de parques eólicos e de mineradoras, que têm causado impactos diversos no cotidiano dessas comunidades. Palavras-chave: Comunidades. Tradição. Conflito.

Abstract: The present article describes itself to analyze the socio-environmental impacts undertaken by several projects of modernization and expropriation of land in common use of traditional pasture communities in the state of Bahia. The pasture fund, so called by its occupants, has its useful life without using the soil, with no fences, for extensive animal husbandry and for fruit extraction, these in turn are consumed and marketed by these residents. These areas are located mainly in the caatinga biome, with their greatest concentration in the north and northeast regions of Bahia and, in general, facing several problems related to the guarantee of land tenure, dating back to the Land Law of 1850 and several subsequent legislation that do not compare or how to use the land. In addition to the absence of fences, we also practice environmental preservation, since we do not use deforestation or predatory hunting. Since the 1970s, these communities face a series of conflicts motivated mainly by the incursion of the grid into their lands, aiming at land concentration and the implementation of modernizing projects such as the construction of large dams, the implantation of parks and miners and miners, that suffer different damages in the daily lives of these communities. Keywords: Communities. Tradition. Conflict.

\section{Introdução}

O fundo de pasto é uma forma secular de utilização comunitária da terra que tem como principal objetivo a produção agropecuária e a preservação ambiental. Tendo destaque a criação extensiva de caprinos,
Artigo está licenciado sob forma de uma licença Creative Commons Atribuição 4.0 Internacional. 
maior fonte de renda dos moradores dessas áreas, são reconhecidas como comunidades tradicionais desde 2007, com os mesmos direitos que os quilombolas, os indígenas, as quebradeiras de coco babaçu, os faxinalenses, os pescadores artesanais, dentre outros povos.

Para Garcez, ${ }^{2}$ a gênese da utilização comunitária da terra encontra-se em dois fatores principais: imprecisão de limites e a indefinição legal dos direitos de propriedade. Ao se formarem, as primeiras comunidades sertanejas foram criando os seus rebanhos no sistema extensivo e os laços de parentesco contribuíram de forma significativa para o surgimento de elo de solidariedade na árdua luta pela sobrevivência no sertão.

Os agricultores que vivem nessas áreas se organizam, atualmente, por meio de associações agropastoris que lhe garantem, após a regularização fundiária junto ao Governo do Estado, o direito de uso e posse dessas terras, bem como o financiamento em órgãos governamentais e não governamentais. Ferraro estima que na Bahia existam 600 (seiscentas) áreas, distribuídas em 28 (vinte e oito) municipios, totalizando aproximadamente vinte e cinco mil familias, ocupando uma área de 1.200 .000 hectares. ${ }^{3} \mathrm{~A}$ maioria das áreas de fundo de pasto 4 localiza-se no semiárido.

De acordo com a professora Jocimara Lobão, o semiárido no estado da Bahia é formado por 258 municípios, compreendendo uma área de $388.274 \mathrm{Km}^{2}$, ou seja, 70\% da área do estado, com uma população de 6.316 .846 habitantes. Isso significa dizer que essa área corresponde a $68 \%$ do território do estado e $48 \%$ de sua população. A visão de semiárido está sempre associada à seca, à pobreza, à fome, e muitas outras mazelas. ${ }^{5}$

O semiárido baiano caracteriza-se pelo clima tropical semiárido, com médias pluviométricas entre 400 e $700 \mathrm{~mm}$ anuais e temperaturas médias anuais elevadas, em torno de $27^{\circ}$ e $29^{\circ} \mathrm{C}$. Além da escassez das chuvas, essas áreas convivem com a irregularidade do período chuvoso, concentrando em cerca de três meses, onde ocorrem chuvas torrenciais, que promovem o desequilibrio ambiental ${ }^{6}$. A preservação promovida nas áreas de fundo de pasto, por não se utilizarem de práticas de desmatamento ou queimadas faz com que a escassez de chuvas ou as chuvas torrenciais não causem tantos efeitos quanto em áreas degradadas e com grande prática erosiva.

A partir da década de 1970, a interferência do Estado com os projetos desenvolvimentistas implantados pelo Regime Militar, ${ }^{7}$ tais como PIN, PROTERRA, POLONORDESTE, PROJETO SERTANEJO etc., fez com que as terras utilizadas para o pastoreio passassem a ser tratadas por agentes externos, (fazendeiros, especuladores, políticos locais), como mercadoria quantificável, objeto de compra e venda. Ao instaurar essa prática, o Estado financiou a invasão de muitas terras e a violação de práticas tradicionais de uso da terra, como o fundo de pasto, além de tratar como arcaicas as atividades produtivas familiares.

Posteriormente, outros programas de caráter desenvolvimentista foram implantados na região e resultaram em diversos conflitos e desafios para inúmeras familias manterem a posse de suas terras. As dificuldades enfrentadas pelas comunidades permitiram a invenção da tradição do fundo de pasto ao longo de sua história. Vários termos deno-

\footnotetext{
GARCEZ, Angelina Nobre Rolim. Fundo de Pasto: um projeto de vida do sertanejo. Salvador: INTERBA/SEPANTEC/CAR, 1987. p. 5. FERRARO JÚNIOR, Luiz A. Entre a invenção da tradição e a imaginação da sociedade sustentável: estudo de caso dos fundos de pasto na Bahia. Tese (Doutorado em Desenvolvimento Sustentável). 2008. 484 f. Universidade de Brasilia - UNB, Brasilia - DF, 2008. p. 85. 4 Ressalta-se que na Região Oeste da Bahia, estão localizadas as Comunidades Tradicionais de Fechos de Pasto, embora tenham trajetória de ocupação e conflitos semelhantes aos das Comunidades Tradicionais de Fundo de Pasto, os Fechos não serão abordados nesta discussão, visto que a pesquisa em curso, iniciada em 2018, para obtenção do doutoramento em História, concentra-se especificamente sobre os fundos de pastos.

5 LOBÃO, Jocimara S. B. et al. Semiárido da Bahia, limites físicos ou sócio-político: uma abordagem geotecnológica para delimitação oficial. Disponivel em: http://www.cpatc.embrapa.br/labgeo/srgsr2/pdfs/poster15.pdf. Acesso em: 1 abr. 2020. p. 1.

6 LOBÃO, Jocimara S. B. et al. Aplicação de técnicas de geoprocessamento para mapeamento geomorfológico do polo de Guanambi: subsídios para o estudo da degradação ambiental e desertificação. Revista Geonorte, Edição Especial, v. 2, n. 4. p. 173-186, 2012.

Projetos melhor detalhados e analisados na perspectiva de suas implicações nas comunidades tradicionais de Fundo de Pasto baianas, no segundo capítulo da minha dissertação, concluida em 2014. DIAS, Simone C. Soares. O pastoreio comunitário em Lage das Aroeiras: Trabalho, sociabilidades - 1970 a 2007. Dissertação (Mestrado em História). Universidade Estadual de Feira de Santana - UEFS. 2014. 149 f. Feira de Santana - BA. Disponivel em: http://www2.uefs.br/pgh/docs/Dissertacao/Disserta\%C3\%A7\%C3\%A30SimoneDias. pdf. Acesso em: 21 jul. 2020
} 
minavam essa forma comunitária de utilizar a terra, porém, diante das ameaças sofridas com o avanço da grilagem, essas comunidades se articularam em torno de uma denominação comum (fundo de pasto) e passaram a reagir em conjunto a essas ameaças.

No intuito de compreender sobre os impactos socioambientais que vêm desestabilizando a garantia de sobrevivência e de continuidade desse modo de utilização da terra, foram mapeados alguns trabalhos, como os de Ferraro, ${ }^{8}$ bem como de outros pesquisadores e movimentos sociais envolvidos. Com essa perspectiva teórico-analítica, apresento como essas comunidades têm se organizado para resistir a essas incursões externas.

\section{Conflitos socioambientais e suas incursões nas terras tradicionais dos fundos de pasto baianos}

\subsection{Grilagem}

Embora a ordem aqui colocada para a discussão dos conflitos e ameaças não defina a sua importância ou a gravidade, acredito que a grilagem é a que atinge a maioria das comunidades, e é, justamente, a prática da grilagem que tem permitido a implantação de diversos projetos modernizantes, pois há relatos dessa forma de expropriação da terra em vários municípios e em várias épocas diferentes, conforme os trabalhos ${ }^{9}$ estudados sobre a temática.

Entre as décadas de 1980 e 1990, os conflitos violentos entre grileiros e trabalhadores foram bem mais intensos, sobretudo nos municípios de Monte Santo, Senhor do Bonfim, Juazeiro e Uauá. Em 1986, foram encontrados pelos integrantes do Projeto Fundo de Pasto, coordenado pelo Instituto de Terras da Bahia (INTERBA), 80 conflitos ativos na região semiárida do Nordeste da Bahia, desse total, 32 estavam ocorrendo em Uauá. A principal causa desses conflitos era a grilagem com a adulteração de documentos, aliada à violência através da utilização de várias formas de intimidação, dentre essas, a contratação de jagunços armados para atemorizar os trabalhadores ${ }^{10}$.

O ano de 1987 também trouxe como marca principal dos conflitos a ação dos grileiros em Uauá, com atritos em $80 \%$ das 72 áreas de fundo de pasto. Já entre 1995 e 2005, de acordo com a Articulação Estadual de Fundo e Fecho de Pasto, houve uma diminuição nesse tipo de embate, embora ainda esteja presente em muitas localidades. Segundo Ferraro, ${ }^{11}$ atualmente existem várias formas de litígio: o modo mais comum relatado é o que ocorre quando da compra de pequenas áreas do fundo de pasto, (ou seu entorno), seguida da ação de variantar, ${ }^{12}$ áreas bem maiores; o pedido de retificação de escritura ${ }^{13}$ também acontece como estratégia de grilar as terras, utilização de escrituras falsas, dentre outras estratégias. Neste trabalho optou-se por abordar um dos conflitos mais extensos enfrentados por uma área ${ }^{14}$ de fundo de pasto - Areia Grande - e que demonstra o quanto a organização da comunidade tem sido um fator imprescindivel para a permanência dos moradores nessas terras.

A disputa ocorrida na região de Areia Grande, que inclui as comunidades de Melancia, Jurema, Salina Branca e Riacho Grande, no municipio de Casa Nova, é um caso de grilagem que se arrasta desde 1979, envolvendo, aproximadamente, duas mil pessoas e quarenta mil hectares de terra. $\mathrm{O}$ conflito se iniciou com a "compra de títulos de posses" das terras utilizadas pelas comunidades para o livre pastoreio, passados à empresa Camaragibe S.A. por políticos e membros das oligarquias regionais que possuiam influência sobre os cartórios locais. A empresa contraiu

\footnotetext{
FERRARO, 2008, p. 132-142.

Garcez (1987), Cotrim (1991), Ehle (1997), Diamantino (2007), Ferraro (2008), Camarote (2010), Dias (2014) e Castor (2017).

10 TORRES, Paulo Rosa. Terra e Territorialidade das Áreas de Fundo de Pastos no Semiárido baiano 1980-2011. Dissertação (Mestrado em Planejamento Territorial e Desenvolvimento Sustentável). Universidade Católica do Salvador - UCSAL. 2011. 134 f. Salvador - BA, 2011, p. 103. 11 FERRARO, 2008, p. 133-134.

12 Picadas é uma denominação que se refere a pequenas estradas que servem para definir os limites de uma propriedade.

13 A comunidade de Monte Alegre, situada no municipio de Monte Santo (BA), é vítima desse processo, pois foi solicitado por um grileiro integrante das famílias da comunidade, que se tornou fazendeiro. Ele se apropriou do formal de partilha e faz uso desse para uma retificação de 130 hectares para 1.200. (GARCEZ, 1987).

14 Em diversos casos, uma mesma área de fundo de pasto abrange outras comunidades que estão localizadas em seu entorno.
} 
altos financiamentos junto ao Banco do Brasil para produção de álcool a partir da mandioca..$^{15} \mathrm{~A}$ injeção de capital para empreendimentos como esse no Sertão do Rio São Francisco aqueceu o mercado de terras e promoveu a expulsão de muitas familias, além de causar muitos danos ambientais, com a destruição de muitas áreas de caatinga para abrigar os plantios. A empresa faliu há cerca de 20 anos e deixou uma divida estimada em R\$ 40 milhões com o Banco do Brasil. ${ }^{16}$

Diante da falência da empresa, as comunidades viveram um período de certa tranquilidade, porém, em 2004, os empresários Alberto Martins Pires Matos e Carlos Nisan Lima e Silva "compraram" a divida junto ao Banco do Brasil por R\$ 639 mil. Eles reivindicam a propriedade da terra na justiça. As comunidades resistiram e sofreram várias invasões violentas, como a ocorrida em 2008, quando o juiz Eduardo Padilha emitiu sentença em favor dos empresários. Durante o cumprimento do mandado de reintegração da posse, com a presença da Polícia Militar, Polícia Civil e Polícia da Caatinga, ${ }^{17}$ houve tentativa de tirar a força as familias da área.

Em fevereiro de 2009, foi assassinada uma das lideranças da comunidade - José Campos Braga, que, na invasão de 2008, teve sua a casa destruída, porém decidiu permanecer na área e lutar pelo lugar que nasceu e onde desejava viver. Zé do Antero, como era conhecido, deixou dez filhos. A opção por continuar na comunidade mesmo tendo sua casa destruída dá a dimensão do sentimento de pertença à terra nutrido pelos moradores do fundo de pasto. Zé morreu em nome do amor que sentia pelo seu lugar, pela sua terra, pela sua gente. Tinha tanta certeza de que a terra pertencia aos seus que não se acovardou, teve a coragem de resistir. Certamente, o sentimento de Zé pela posse da terra onde nasceu é semelhante ao descrito por Steinbeck:

Se um homem tem um pedaço de terra, esse pedaço de terra é ele mesmo, faz parte dele mesmo, é como ele mesmo. Se é dono de uma terra assim, pode andar nela, tratar dela, e ficar triste quando ela não produz, e contente quando chove. Está sempre satisfeito, porque a terra é dele, é parte dele, é igual a ele. ${ }^{18}$

Somente após o assassinato, o processo de discriminação das terras públicas realizado pelo Estado concluiu que os títulos da Camaragibe eram falsos e a área fazia parte das terras públicas devolutas. ${ }^{19}$ Por conseguinte, novos capítulos do conflito continuaram a surgir, pois as ações discriminatórias de titularidade de terra só podem ocorrer quando não há nenhuma contestação, e, diante do processo movido pelos empresários, o impasse continuou. Outro agravante na situação foi a atuação do juiz Padilha no caso, uma vez que realizou visitas na área sem comunicado prévio e declarou, em entrevista ao site Repórter Brasil, que a utilização da área pelas familias teria sido "mascarada". 20 Candido da Costa e Silva, define o porquê desse tipo de atitude que privilegia os poderosos:

Entre os que detém o poder, o jogo de influências decidirá pelo mais forte. E a força está no dinheiro. Via de regra, a justiça sanciona os interesses do mandonismo local. Abandonado as suas próprias dores, desatendido nos reclamos contra espoliações e descasos, vive o sertanejo. As conveniências do chefe norteiam as providencias do Delegado (ou a falta delas), inspira a eloquência inútil do Promotor, até os despachos incolores do Juiz.. ${ }^{21}$

\footnotetext{
15 Essa tentativa de produzir álcool a partir da mandioca ficou nacionalmente conhecida como o "escândalo da mandioca", no qual a empresa Camaragibe S.A. foi uma das envolvidas, assim como latifundiários nordestinos que forjavam perdas de safras para não quitar os empréstimos e continuarem a receber os incentivos ligados ao Pró-álcool, durante o regime militar. (DIAMANTIDO, Pedro e MAGALHÃES FILHO, Paulo A. Grilagem de terras ameaça fundos de pasto na Bahia. 2008). Disponivel em: http://pambazuca.org/pt/category/ comment/52758. Acesso em: 10 jan. 2020.

16 REIMBERG. Mauricio. Área em disputa no sertão é palco de morte de trabalhador rural. 2009. Disponivel em: http://reporterbrasil.org. $\mathrm{br} / 200 \mathrm{~g} / 02 / \mathrm{rea}-\mathrm{em}$-disputa-no-sertao-e-palco-de-morte-de-trabalhador-rural/. Acesso em: 10 jan. 2020.

17 Denominação popular para Companhia Independente de Policiamento Especializado - Caatinga. A CIPE/Caatinga, juntamente com as demais Companhias Independentes (Cerrado, Oeste, Mata Atlântica, Litoral Norte, Sudoeste, Polo Industrial e Cacaueira), integra a estrutura da Polícia Militar da Bahia e foi criada com o objetivo de atuar nos mais longínquos rincões do estado e é acionada para participar de operações diversas nas regiões em que atuam. POLiCIA MILITAR DA BAHIA. Histórico. Disponivel: http://www.pm.ba.gov.br/index. php?option=com_content\&view=category\&id=94\&ltemid=547. Acesso em: 21 de jul. 2020.

18 STHEINBECK, John. As vinhas da Ira. Rio de Janeiro: Bestbolso, 2008. p. 47.

19 PYL. Bianca. Ação direta de juiz acua comunidades de fundo de pasto. 2010. Disponivel em: http://reporterbrasil.org.br/2010/04/ acao-direta-de-juiz-acua-comunidades-de-fundo-de-pasto/. Acesso em: 10 abr. 2020.

20 PYL, op. cit., p. 4.

${ }_{21}$ COSTA E SILVA, Candido da. Roteiro da vida e da morte: um estudo do catolicismo no sertão da Bahia. São Paulo: Ática, 1982. p. 79.
} 
Diante do comportamento do magistrado, as familias entraram com pedido de suspensão do julgamento da ação discriminatória questionando a imparcialidade do juiz.

A área, marcada há mais de 40 anos pelas investidas de grileiros, voltou a ser alvo de ameaças em janeiro de 2013, quando três homens não identificados acompanhados de um oficial de justiça, dois policiais armados e um chaveiro entraram na área, sem apresentar mandado judicial, e no dia seguinte três homens invadiram uma propriedade e perfuraram uma cisterna com mais de vinte tiros. ${ }^{22}$

Durante a tramitação da Ação Discriminatória Judicial (2008-2016), diversas provas foram produzidas pelo Estado da Bahia e pelas Associações Comunitárias de Areia Grande, e em nenhum momento, os empresários conseguiram comprovar a legalidade dos registros que embasam o suposto direito de propriedade e as matrículas do imóvel foram anuladas. Porém, em 2016, um juiz, deliberadamente, desconsiderou todo esse conjunto de provas e proferiu sentença afirmando que a área é propriedade privada dos empresários e negando o pedido do Estado da Bahia. Dia 26 de março de 2017, houve determinação que os empresários fossem emitidos na posse na área, com uso de força policial. ${ }^{23}$ As familias resistiram, continuam resistindo e aguardando o desfecho de novas ações, enquanto isso, a grilagem também resiste.

A exposição do caso de Areia Grande foi feita com o intuito de demonstrar o impacto da grilagem na vida de comunidades de fundo de pasto. A lentidão do Estado do Bahia em realizar a regularização ${ }^{24}$ de dezenas de áreas, aliada à atuação duvidosa da justiça em casos como esse, tem deixado a mercê do medo e da violência milhares de familias sertanejas que utilizam a terra para produzir. A trajetória de luta de Areia Grande demonstra que a resistência da comunidade, mesmo diante de um conflito tão longo, continua firme e organizada para garantir a posse da terra e da continuidade do seu modo de vida, que é utilizar a terra comunitariamente.

\subsection{Barragens}

A construção de grandes barragens tem gerado muitos efeitos nocivos às populações que ocupavam as terras antes das obras, pois além de serem deslocadas do seu lugar de origem e de vivências diversas, muitas vezes, as compensações oferecidas pelos governos não trazem os benefícios esperados. Em sua tese de doutoramento, Ely de Souza Estrela, trouxe à tona o sofrimento de várias familias que saíram das suas terras para dar lugar às águas a serem represadas na Barragem de Sobradinho. As compensações financeiras, por meio das indenizações, foram incipientes e as reparações sociais jamais ocorreram, uma vez que as agrovilas de Serra do Ramalho, para onde foram alocados centenas de trabalhadores, eram lugares, para a maioria, de miséria, de decepção, sofrimento.

\begin{abstract}
Identificados os atingidos pela barragem, os órgãos governamentais envolvidos no processo de sua construção empreenderam as desapropriações, dando ensejo ao pagamento de indenizações. Somente 13\% das terras eram tituladas, seus proprietários seriam indenizados com possibilidades imediatas de reorganizar suas vidas. E os foreiros-posseiros-beraderos? Estes se surpreenderam com a informação de que não teriam suas terras de trabalho indenizadas. Receberiam apenas indenizações adstritas às benfeitorias. As indenizações que em principio deveriam reparar as perdas dos desapropriados e possibilitar-lhes o recomeço da vida, tornaram-se mais um fator de espoliação dos camponeses. ${ }^{25}$
\end{abstract}

No caso especíico do fundo de pasto, a Barragem de Sobradinho inundou terras pertencentes à comunidade Areia Grande, em Casa Nova, "teve gente que até morreu, tomou veneno por desgosto" (Valério Rocha, ex-presidente da União das Associações de Fundo de Pasto de Casa Nova,

\footnotetext{
22 BORGES, José Carlos. Comunidades de Areia Grande clamam por justiça no municipio. Disponivel em: http://zecarlosborges.blogspot com.br/2013/03/casa-nova-ba-comunidades-de-areia.html. Acesso em: 10 abr. 2020.

23 OLIVEIRA, Cláudio D.; ROCHA, Marina. Estudo de Caso Areia Grande: Resistir para existir. A luta no sertão baiano é pelo Fundo de Pasto! Disponivel em: https://www.porlatierra.org/docs/b26b492fo8dg6f7c25b4774cfe442fbe.pdf. Acesso em: 23 abr. 2020. p. 5-10.

24 A regularização das áreas das comunidades tradicionais de fundo e fecho de pasto, possui amparo na Constituição do Estado da Bahia, de 1989, que em seu artigo 178, reconhece esse direito, bem como na Lei n. ${ }^{\circ} 12.910$, de 2013 , que regulamenta esse direito.

25 ESTRELA, Ely de Souza. Sobradinho: a retirada de um povo. Salvador: Eduneb, 2010. p. 107
} 
em entrevista a André Campos, Repórter Brasil, 2009) ${ }^{26}$. A obra fez com que acontecesse um avanço da grilagem nas terras de uso comunitário em Juazeiro por causa do crescimento das áreas irrigadas. A Barragem de Itaparica, ao provocar a valorização das terras em torno das áreas represadas, oportunizou a grilagem de muitas terras, contribuindo para o fim de muitas áreas de fundo de pasto nos municípios de Abaré, Macururé, Chorrochó, Rodelas, Paulo Afonso e Glória.

Um novo projeto de aproveitamento das águas do Rio São Francisco para produção de energia elétrica trouxe bastante ameaça áreas de fundo de pasto em Juazeiro e Curaçá. O empreendimento, denominado de Barragem de Riacho Seco e Pedra Branca, estava previsto para atingir, além desses municípios localizados na Bahia, os municípios de Orocó, Santa Maria da Boa Vista, Lagoa Grande e Petrolina, em Pernambuco.

Nos últimos anos, as organizações dos agricultores sentiram necessidade de construir estratégias voltadas para o enfrentamento das construções das barragens de Riacho Seco e Pedra Branca e, ao mesmo tempo, questionar o modelo de desenvolvimento e o modelo energético brasileiro. Pelo histórico de construção de barragens no Brasil, existe a preocupação com as violações dos direitos das familias que serão atingidas pela barragem. ${ }^{27}$

A obra em questão, caso ocorresse, deslocaria, de acordo com o Movimento dos Atingidos por Barragens (MAB), ${ }^{28}$ cerca de vinte mil pessoas, dentre elas, moradores de diversas comunidades de fundo de pasto do município. Além dos atingidos diretamente pela barragem, as demais comunida- des temem pela grilagem de suas áreas em consequência da valorização das terras do município.

Em 2015, após várias mobilizações, uma ação movida pela ONG Terra de Direitos e pelas comunidades quilombolas de Inhanhum, Serrote e Cupira, localizadas no municipio de Santa Maria da Boa Vista (PE), conseguiu a garantia por parte do Instituto Brasileiro do Meio Ambiente e dos Recursos Naturais Renováveis (IBAMA), que o projeto seria arquivado, conforme parecer expedido pelo Ministério Público Federal. ${ }^{29}$

\subsection{Energia eólica}

A grilagem e a construção de barragens são ameaças presentes no cotidiano de muitas comunidades há vários anos, com conflitos que se arrastam por décadas. Recentemente, em nome do desenvolvimento por meio da produção de energia, uma nova ameaça ronda o fundo de pasto: a energia eólica. A utilização dos ventos para produção de "energia limpa", ${ }^{30}$ denominada energia eólica, não tem demostrado, na prática, ser tão limpa assim. De acordo com a CPT ${ }^{31}$, na comunidade de São Gonçalo da Serra, em Sobradinho, que utilizam áreas abertas há mais de 200 anos, e foram tituladas como áreas de fundo de pasto há mais de doze, recentemente apareceram "novos donos" para grilar as terras onde serão instaladas as torres.

Na Bahia, o setor que gera energia através dos ventos deu um salto nos últimos quatro anos. Com 10\% do potencial nacional de energia eólica, o estado é o maior polo brasileiro de

26 CAMPOS, André. Comunidades de Fundo de Pasto resistem a pressões. 2009. Disponivel em: http://reporterbrasil.org.br/200g/og/ comunidades-de-fundos-de-pasto-resistem-a-pressoes. Acesso em: 28 mar. 2020.

27 ASA - ARTICULAÇÃO NO SEMIÁRIDO BRASILEIRO. Resistência das comunidades ribeirinhas à construção das hidrelétricas de Riacho Seco e Pedra Branca. 2010. Disponivel em: http://7enconasa.wordpress.com/2010/03/17/resistencia-das-comunidades-ribeirinhas-a-construcao-das-hidroeletricas-de-riacho-seco-e-pedra-branca. Acesso em: 27 mar. 2020.

28 MAB - MOVIMENTO DOS ATINGIDOS POR BARRAGENS. Na Bahia, atingidos por barragens, marcham na BR 210. 2010. Disponivel em: http://www.mabnacional.org.br/noticia/na-bahia-atingidos-por-barragens-marcham-na-br-210. Acesso em: 26 mar. 2020.

29 BRASIL. Ministério Público Federal (Procuradoria da República Polo Petrolina/Juazeiro). Promoção de Arquivamento (Ref.: Inquérito Civil n. 1.26.001.000028/2009-11). 27 de abril de 2015. Disponivel em: file:///C:/Users/Pc/Downloads/Arquivamento 62_2016-1.26.001.00002820011_UH\%20Riacho\%20Seco\%20e\%20Pedra\%20Branca_arquivamento\%20e\%20posterior\%20convers\%C3\% $30 \% 20$ em\%20PA-1.pdf. Acesso em: 26 abr. 2020

30 O documentário Energia Eólica: a caçada pelos ventos, produzido pela CPT - Bahia e dirigido por Thomas Bauer, traz importantes relatos a respeito da produção energética a partir dos ventos vista por diversos ângulos e permite perceber que, assim como as hidroelétricas, as empresas e o governo divulgam apenas os ganhos econômicos e não tornam públicas as dificuldades que esses empreendimentos causam ao cotidiano dos moradores locais, como o caso de grilagem nas terras do municipio de Sento Sé, e a grande quantidade de água utilizada para erguer as torres, enquanto milhares de famílias estão sofrendo com a escassez de água no semiárido. O documentário está disponivel em: BAUER. Thomas. Energia Eólica: a caçada pelos ventos [S. l.: s. n.], 16 de maio de 2013 . Publicado pelo canal Thomas Bauer. Disponivel em: https://www.youtube.com/watch?v=sgonKSlbgoQ. Acesso em: 25 jan. 2020.

31 CPT - COMISSÃO PASTORAL DA TERRA - Diocese de Juazeiro - BA. Depois da barragem, as torres. 2013. Disponivel em: http://cptjuazeiroba.blogspot.com.br/search?q=energia+e\%C3\%B3lica. Acesso em: 11 jan. 2020. 
investimentos no ramo, em que cada megawatt produzido por hora custa cerca de R \$99,00. Ao sabor do vento, grande parte desses recursos sairá dos cofres públicos. E o que é pior, sem uma consulta pública, sobretudo às comunidades, a maioria de familias camponesas que conservam modos de vida tradicionais, como as de fundo de pasto. ${ }^{32}$

Além de Sobradinho, os municipios de Campo Formoso, Sento Sé e Casa Nova, que possuem comunidades de fundo de pasto, também receberão projetos de produção de "energia limpa" que contam com altos investimentos públicos e dada a rapidez de suas operações, é possivel afirmar que os impactos para o fundo de pasto e para outras formas de utilização da terra presente nos diversos municípios baianos, não foram devidamente estudados.

A desconfiança de ambientalistas é de que esses estudos foram feitos às pressas, já que a expansão das eólicas acontece com muita rapidez. O primeiro leilão de energia eólica do governo federal foi feito em 2009. Em menos de dois anos, mais de 50 torres foram erguidas em toda a Bahia. O Plano Decenal de Expansão de Energia, da EPE, mostra que a região de Boqueirão da Onça ${ }^{33}$ é um dos principais focos de eólicas no Estado. Já foram instalados 48 MW em Sobradinho, 86 MW em Sento Sé e $180 \mathrm{MW}$ em Casa Nova. ${ }^{34}$

Enquanto os processos de titulação das áreas de fundo de pasto em nome das associações que representam as comunidades se arrastam desde 1989, as dotações orçamentárias para projetos de produção de energia são autorizadas de forma rápida e eficiente. Enquanto isso, as comunidades, que tanto esperam ver uma equipe da Coordenação de Desenvolvimento Agrária (CDA), responsável pela regularização das áreas de fundos de pasto, para finalmente terem garantida a posse da terra, deparam-se com equipes de empresas como Iberdrola, Neoenergia, Renova Energia, Casa dos Ventos, entre outras, demarcando áreas que não possuem, para implantar o desenvolvimento energético, que cresce rapidamente a cada ano.

\begin{abstract}
A Bahia conta com 56 parques em construção (total de $942 \mathrm{MW}$ ). Segundo a Aneel, ainda para a Bahia há outros 35 parques eólicos (660 MW) com construção ainda não iniciada. Quando concluídos, provavelmente em 2023. o estado terá 229 parques com capacidade total para gerar 6.270 MW. Os investimentos totais na Bahia, até 2023, devem ficar em torno de $\mathrm{R} \$ 7,49$ bilhões, com a geração de aproximadamente 26,7 mil empregos em toda a cadeia produtiva, sobretudo em cidades e comunidades rurais próximas aos parques. ${ }^{35}$
\end{abstract}

Além da grilagem, da construção de barragens e da energia eólica, nos estudos realizados até então, estão presentes outros conflitos por causa da exploração mineral, da produção de agrocombustiveis, e da utilização da catinga para a produção de carvão que, também estão ameaçando a existência dos fundos de pasto. Ressalta-se que esse cenário de insegurança é fruto das diversas formas de imposição realizadas pelo poder público para levar o "progresso" aos mais diversos territórios brasileiros. Utilizando a "ordem", ao invés do respeito, o governo tem promovido o desenvolvimento desqualificando gradativamente os diversos saberes comunitários e promovendo gradativamente a destruição ambiental em diversas regiões. Como resultado desse processo, milhares de familias são despossuidas de suas terras e consequentemente de suas vidas.
Ibid.

33 O Boqueirão da Onça é uma região de mais de um milhão de hectares de vegetação nativa bem conservada, próximo ao local onde o Rio São Francisco foi barrado para a construção da hidrelétrica de Sobradinho, com poucos povoados humanos e uma biodiversidade muito grande para os padrões do semiárido brasileiro. Ambientalistas reivindicam a criação de uma unidade de conservação no local. e um projeto para transformar o Boqueirão em Parque Nacional existe desde 2002. No entanto, enquanto o projeto não anda, pesquisadores temem que esse santuário de conservação possa estar ameaçado, ironicamente, por outro campeão ambiental: a energia dos ventos. As usinas eólicas não lançam gases poluentes que causam o aquecimento global. Mas a sua construção também causa impacto - usa-se concreto, ferro, e muitas vezes é preciso derrubar a mata nativa para erguer as torres. Acontece que ao mesmo tempo que o Boqueirão da Onça é uma área prioritária para a conservação, é também uma das regiões com maior potencial de geração de energia pelo vento do Brasil. CALIXTO, Bruno. A onça-pintada contra energia eólica. Disponivel em: http://colunas.revistaepoca.globo.com/planeta/2013/03/04/no-interior-da-bahia-onca pintada-disputa-espaco-com-torres-eolicas. Acesso em: 11 jan. 2020.

34 Ibidem.

35 BITTENCOURT, Mário. Bahia vai assumir a liderança do setor de energia eólica do país ainda neste semestre, 2019. Disponivel em: https://www.correio24horas.com.br/noticia/nid/bahia-vai-assumir-a-Lideranca-do-setor-de-energia-eolica-do-pais-ainda-neste-semestre/. Acesso em: 28 abr. 2020. 


\subsection{Mineração}

A mineração na Bahia é incentivada pela Companhia Baiana de Pesquisa Mineração (CBPM), que desenvolve pesquisas no subsolo baiano, abrindo as "descobertas" aos investimentos privados. Cerca de $70 \%$ do subsolo baiano está dividido e nas mãos da iniciativa privada. ${ }^{36} \mathrm{O}$ estado tem a maior diversidade mineral do pais, com quarenta substâncias. É o quarto maior produtor nacional e está prestes a se tornar o terceiro. É o terceiro maior depósito de ferro do país - que segue a Serra Geral, na margem direita do Rio São Francisco, até as bordas do Lago de Sobradinho - e o primeiro em requisições para pesquisa mineral. ${ }^{37}$

Multiplicam-se, Bahia afora, os empreendimentos minerários e as obras de infraestrutura, públicas ou financiadas com recursos públicos, para viabilizá-los. Aqui já operam 340 empresas de mineração, em cem municípios, que geram apenas oito mil empregos. Preveem-se investimento de 6.5 bilhões de dólares no setor, entre 2012 e 2016 - 8,71\% do total nacional ( 75 bilhões de dólares). Isto significa que cerca de $25 \%$ de todo investimento econômico no Estado nesse periodo. ${ }^{38}$

O crescimento da atividade mineral na Bahia, no Brasil e no mundo, se deve à forte demanda por "commodities" (matérias-primas comuns, cultivadas ou extraídas da natureza, com algum grau de industrialização, negociadas no mercado global) minerais, somada à escassez de estoques e insuficiência no abastecimento de algumas delas, principalmente daquelas mais utilizadas pela indústria básica, como o níquel, o ferro, o zinco, o alumínio, o chumbo, o cobre, entre outros, situação que aumentou exorbitantemente seus preços. Essa demanda por abastecimento tem feito crescer a pressão pelo não reconhecimento dos territórios tradicionais, especialmente, no sul do Maranhão, no norte do Tocantins e no oeste da Bahia e de Pernambuco. As comunidades de fundos de pasto também têm sido alvo dessa pressão. Esse modelo de desenvolvimento em curso no país que beneficia desmedidamente o agro-hidronegócio, as imobiliárias, as grandes indústrias e a exploração mineral, tem ameaçado a existência e o reconhecimento dos direitos territoriais de diversas comunidades tradicionais brasileiras. ${ }^{39}$

O fato é que se, por um lado, o governo baiano parou com a regularização dos fundos de pasto, desde 2007, por outro, continua licenciando as atividades de exploração mineral, criando incentivos para que empresas venham investir e estimulando a produção de monocultura e oleaginosas em espaços com grande presença de fundos de pasto. ${ }^{40}$ É preciso destacar que a exploração mineral já vem apresentando diversos impactos negativos nas comunidades de fundo de pasto da região de Juazeiro. Foi o que mostrou o diagnóstico realizado pela CPT de Juazeiro,,$^{41}$ confeccionado a partir de entrevistas com informantes locais, sindicatos, associações, reuniões com equipes paroquiais, assembleias, seminários com trabalhadores rurais, visitas aos locais de pesquisa e exploração de minérios. Esse diagnóstico identifica impactos negativos dessa atividade no meio ambiente e nas comunidades rurais, como: contaminação de aguadas e a consequente morte de animais, desmatamento de árvores nativas e problemas de saúde nas populações locais, resultado do pó da extração dos minérios. Outro problema se refere aos locais autorizados para pesquisas. Muitas delas são autorizadas para ocorrer nas margens de riachos e rios, dentro de áreas de fundos de pasto ou em assentamentos de reforma agrária. ${ }^{42} \mathrm{Um}$ depoimento presente no estudo realizado por Alfredo Wagner nas comunidades de fundo de pasto, evidencia os problemas enfrentados.

36 SANTOS, Cirlene Jeane Santos e. Fundos de Pasto: Tecitura da resistência, rupturas e permanências no tempo-espaço desse modo de vida camponês. Tese (Doutorado em Geografia). 2010. 290 f. Universidade de São Paulo, São Paulo, 2010. p. 232.

37 REVISTA ALUMEIA. Mineração: progresso ou destruição. Salvador: CPT, 2013. p. 12.

38 Ibidem, p. 13.

39 Ibidem, p. 203

40 Ibidem.

${ }^{41}$ CPT. Mineração na região de Juazeiro: avanços, impactos e resistência das comunidades rurais, 2009. Disponivel em: http://wwww. cptba.org.br/joomla15/download/diagnostico_mineracao_juazeiro_jul200g.pdf. Acesso em: 9 jun. 2019.

42 REIS, Angélica Santos. Fundos de Pasto baianos: um estudo sobre regularização fundiária. Dissertação (Mestrado em Ciências Sociais). Universidade Federal da Bahia - UFBA, 2010. 242 f. Salvador - BA. p. 203-204. 
As mineradoras compram pequenas áreas por um preço muito baixo e depois as crescem invadindo terras de uso comum e serras. Isso acontece em algumas localidades porque quem vendeu as terras acreditava na propaganda feita de empregos e salários. Os empregos são ocupados por gente de fora e o que resta é poluição. ${ }^{43}$

No município de Sento Sé, as pesquisas e exploração mineral colocaram em risco a integridade do modo de vida dos moradores do fundo de pasto. Em abril de 2010, homens armados invadiram o fundo de pasto Campo Largo ameaçando os camponeses, a polícia foi acionada e os capturou. Em depoimento revelaram que estavam a serviço da "Biobrax", que segundo os camponeses é uma empresa do setor de mineração. ${ }^{44}$

Antonino (2017) 45 destaca que os municipios de Jaguarari, Curaçá, Campo Formoso, Senhor do Bonfim e Campo alegre de Lourdes, com forte presença de comunidades de fundo de pasto, têm sido palco nos últimos anos de diversos conflitos envolvendo a exploração mineral, com destaque para o município de Curaçá, que possui 41 (quarenta e uma) comunidades de fundo de pasto, evidenciando a ameaça ambiental e social que essas comunidades estão expostas, caso todos os requerimentos de exploração em curso, se concretizem.

No ano de 2015, o municipio figurou em segundo lugar na lista com maior número de processos de Requerimento de pesquisa na Bahia - somando 149 novos processos no DNPM. Segundo estimativas quantitativas, 83\% do território já está mapeado com algum tipo de processo em andamento e diversos estão nas margens do Rio São Francisco. Alguns conflitos minerários já foram relatados em Curaçá, mesmo na fase inicial de pesquisa e de prospecções geológicas. O total de processos em andamento somam-se 491. Sendo 19 substâncias pesquisadas, nas quais o Granito, o Mármore, o Cobre, o Ferro e o Fosfato representam 90\% dessa totalidade (446 processos). Os Requerimentos de Autorização de Pesquisa são os quinam atualmente, totalizando 427 casos $(87 \%)$, indicando o potencial minerário e o efervescer pulsante da extração nesses territórios que podem vivenciar futuras am- putações e perpetuações da pobreza, apesar da "riqueza" mineral indicada.

Os casos citados oferecem uma dimensão das incursões realizadas pelas mineradoras que com a autorização do poder público e mesmo sem ela, utilizam de força e de seu poder de persuasão ou encantamento (pois muitos se iludem com sua propaganda de geração de empregos) para desrespeitar o modo de vida e de produção das comunidades, destruindo o que elas têm de mais precioso, o acesso à terra.

\section{Considerações finais}

Os impactos causados pelos empreendimentos citados são diversos, vão desde a danificação da flora da caatinga, ocasionando áreas desmatadas, bem como em processo de diversificação. Além disso, atividades modernizantes, com forte apelo econômico como a mineração e a energia eólica tendem a causar desentendimentos entre os moradores das comunidades, desestabilizando seu uso comunitário da terra e possibilitando a desarticulação dos debates coletivos em prol do desenvolvimento local.

A lentidão do estado da Bahia em garantir a ampla regularização da posse dessas terras utilizadas comunitariamente, tem deixado milhares de familias a mercê de práticas predatórios em seu ambiente natural, bem como tem facilitado a grilagem e a invasão de suas terras por agentes externos que através da violência, têm conseguido enfraquecer a luta e a coesão desse grupo pela manutenção do seu modo de vida. Todos esses projetos modernizantes têm impactado diretamente na organização social dos agricultores que tem o trabalho comunitário como elemento primordial e indispensável para manutenção de suas terras para o criatório extensivo dos animais pautado nos laços de parentesco, na solidariedade e no respeito mútuo. Ressalta-se que, o apoio de diversas entidades, a exemplo da Articulação Estadual de Fundo de Pasto, Comissão Pastoral

\footnotetext{
43 ALMEIDA, Alfredo Wagner B. de e MARIN, Rosa Azevedo. Fundo de Pasto: nosso jeito de viver no sertão. Projeto Nova Cartografia Socia dos Povos e Comunidades Tradicionais. UFAM, 2007. Fascículo 2 - Fundo de Pasto, p. 9.

44 SANTOS e SANTOS, op. cit., p. 243.

45 ANTONINO, Lucas Azenha. Mineração e expoliação territorial na Bahia. Disponivel em: https://singa2017.files.wordpress.com/2017/12/ gt11_1506019582_arquivo_singa2017completo_lucaszenhaantonino.pdf. Acesso em: 28 de abr. 2020
} 
da Terra (CPT), dentre outras, pode ser considerado como fator preponderante para resistir a esses diversos conflitos.

Diante dos estudos realizados é possivel afirmar que a garantia da posse da terra é um dos grandes impasses para que haja a continuidade do modo de vida dessas centenas de comunidades baianas que continuam resistindo bravamente às diversas tentativas de invasão de suas terras e aos diversos projetos, que com o discurso do desenvolvimento, têm atuado para destruição ambiental e colocado em risco a produção comunitária dessas milhares de familias. Para continuarem a existir para as futuras gerações, observou-se que é imprescindivel uma articulação cada vez maior entre as comunidades praticantes, além de políticas públicas ambientais, hídricas, educacionais, sociais e culturais que garantam que as familias sertanejas vivam dignamente na terra onde nasceram e sonham em ver os seus descendentes crescerem e se multiplicarem enquanto trabalhadores rurais respeitados e com o seu "jeito" de utilizar a terra comunitariamente, plenamente reconhecido e valorizado.

\section{Referências}

ALMEIDA, Alfredo Wagner B. de; MARIN, Rosa Azevedo. Fundo de Pasto: nosso jeito de viver no sertão. Projeto Nova Cartografia Social dos Povos e Comunidades Tradicionais. Brasília, DF: UFAM, 2007. (Fundo de Pasto, Fascículo 2).

ANTONINO, Lucas Azenha. Mineração e expoliação territorial na Bahia. In: SIMPÓSIO INTERNACIONAL DE GEOGRAFIA AGRÁRIA - SINGA, 8., 2017, Curitiba. Anais eletrônicos [...]. Curitiba: [s. n.], 2017. Disponivel em: https://singa2017.files.wordpress.com/2017/12/ gt11_1506019582_arquivo_singa2017completo_lucaszenhaantonino.pdf. Acesso em: 28 abr. 2020.

ASA - ARTICULAÇÃO NO SEMIÁRIDO BRASILEIRO Resistência das comunidades ribeirinhas à construção das hidrelétricas de Riacho Seco e Pedra Branca. In: EnconASA, Juazeiro, 2010. p. 1-3. Disponivel em: http://7enconasa.wordpress.com/2010/03/17/resistencia-das-comunidades-ribeirinhas-a-construcao-das-hidroeletricas-de-riacho-seco-e-pedra-branca/. Acesso em: 27 mar. 2020.

BAUER. Thomas. Energia Eólica: a caçada pelos ventos. [S. l.: s. n.], 16 de maio de 2013. 1 vídeo (25m $30 \mathrm{~s}$ ). Publicado pelo canal Thomas Bauer. Disponivel em: https://Www.youtube.com/watch? V=s9onKSlbgoQ. Acesso em: 25 jan. 2020.
BITTENCOURT, Mário. Bahia vai assumir a liderança do setor de energia eólica do pais ainda neste semestre. Correio, 11 jan. 2019. Disponivel em: https://www. correioz4horas.com.br/noticia/nid/bahia-vai-assumir-a-Lideranca-do-setor-de-energia-eolica-do-pais-ainda-neste-semestre/. Acesso em: 28 abr. 2020.

BORGES, José Carlos. Comunidades de Areia Grande clamam por justiça no municipio. Blog do Ze Carlos Borges, mar. 2013. Disponivel em: http://zecarlosborges. blogspot.com.br/2013/03/casa-nova-ba-comunidades-de-areia.html. Acesso em: 10 abr. 2020.

BRASIL. Ministério Público Federal. Procuradoria da República Polo Petrolina/Juazeiro. Inquérito Civil $n^{\circ}$ 1.26.001.000028/2009-11 (Ref.: Inquérito Civil n. 1.26.001.000028/2009-11). Promoção de Arquivamento. 27 de abril de 2015. Disponivel em: http://www.prpe. mpf.mp.br/internet/index.php/internet/Petrolina-Juazeiro/Areas-de-Atuacao/Comunidades-Indigenas-e-Minorias/Atividade-extrajudicial/2015/Inquerito-Civil-n1-1.26.001.000028-2009-11. Acesso em: 26 abr. 2020

CALIXTO, Bruno. A onça-pintada contra energia eólica. Época, 04 mar. 2013. Coluna Planeta. Disponivel em: http:// colunas.revistaepoca.globo.com/planeta/2013/03/04/ no-interior-da-bahia-onca pintada-disputa-espaco-com-torres-eolicas/. Acesso em: 11 jan. 2020.

CAMAROTE, Elisa Machado. Lages das Aroeiras: Territorialização, parentesco e produção em uma comunidade baiana de fundo de pasto. Dissertação (Mestrado em Ciências Sociais). 2010. 198 f. Universidade Federal da Bahia - UFBA, Salvador/BA, 2010.

CAMPOS, André. Comunidades de Fundo de Pasto resistem a pressões. In: Reporter Brasil, São Paulo, 24 set. 2009. Disponivel em: http://reporterbrasil.org. $\mathrm{br} / 200 \mathrm{~g} / 0 \mathrm{~g} / \mathrm{comunidades}-\mathrm{de}$-fundos-de-pasto-resistem-a-pressoes. Acesso em: 28 mar. 2020.

CASTOR, Jocelmo Araújo. Representação sócioambiental e cultural dos criadores ao modo do Fundo de Pasto, Glória - BA. 85 f. Dissertação (Mestrado Acadêmico em Ecologia Humana e Gestão Sócioambiental). Universidade do Estado da Bahia - UNEB, Campus Paulo Afonso, Paulo Afonso, 2017.

COSTA E SILVA, Candido da. Roteiro da vida e da morte: um estudo do catolicismo no sertão da Bahia. São Paulo: Ática, 1982.

COTRIM, Dione Vinhas Nascimento. O pastoreio Comunitário em Uauá: uma expressão da subordinação do trabalho ao capital. Dissertação (Mestrado em Ciências Sociais). 1991. 108 f. Salvador, UFBA.

CPT - COMISSÃO PASTORAL DA TERRA - Bahia. Mineração na região de Juazeiro: avanços, impactos e resistência das comunidades rurais. [S. l.]: CTP, 2009. Disponivel em: http://www.cptba.org.br/joomla15/ download/diagnostico_mineracao_juazeiro_jul2009. pdf. Acesso em: og jun. 2019.

CPT - COMISSÃO PASTORAL DA TERRA - Bahia e Sergipe - Diocese de Juazeiro - BA. Depois da barragem, as torres. Blog da Comissão pastoral da Terra de Juazeiro, Juazeiro, BA, 11 jun. 2013. Disponivel em: http://cptjuazeiroba.blogspot.com.br/search?q=energia + e\%C3\%B3lica. Acesso em: 11 jan. 2020. 
DIAMANTINO, Pedro Teixeira. "Desde o raiar da aurora o sertão tonteia": caminhos e descaminhos da trajetória sócio-jurídica das comunidades de fundo de pasto pelo reconhecimento de seus direitos territoriais. Dissertação (Mestrado em Direito). 2007. 143 f. Universidade de Brasilia - UNB, Brasília - DF.

DIAMANTIDO, Pedro; MAGALHÃES FILHO, Paulo A. Grilagem de terras ameaça fundos de pasto na Bahia. [S. l: s. n.], 2008. Comentário. Disponivel em http:// pambazuca.org/pt/category/comment/52758. Acesso em: 10 jan. 2020.

DIAS, Simone C. S. Dias. O pastoreio comunitário em Lage das Aroeiras: trabalhos, sociabilidades, desafios. 2014. 149 f. Dissertação (Mestrado em História). Universidade Estadual de Feira de Santana - UEFS, Feira de Santana - BA, 2014. Disponivel em: http://Www2.uefs. br/pgh/docs/Dissertacao/Disserta\%C3\%A7\%C3\%A3oSimoneDias.pdf. Acesso em: 21 jul. 2020.

EHLE, Paulo. Canudos: Fundo de Pasto no Semiárido. Paulo Afonso: Fonte Viva, 1997.

ESTRELA, Ely de Souza. Sobradinho: a retirada de um povo. Salvador: Eduneb, 2010.

FERRARO JÚNIOR, Luiz A. Entre a invenção da tradição e a imaginação da sociedade sustentável: estudo de caso dos fundos de pasto na Bahia. Tese (Doutorado em Desenvolvimento Sustentável). 2008. 484 f. Universidade de Brasília - UNB, Brasilia - DF, 2008.

GARCEZ, Angelina Nobre Rolim. Fundo de Pasto: um projeto de vida do sertanejo. Salvador: INTERBA/ SEPANTEC/CAR, 1987.

HOBSBAWN, Eric J. A Invenção das Tradições (Introdução). In: HOBSBAWN, Eric; RANGER, Terence (org.). A Invenção das Tradições. Tradução de Celina Cardim Cavalcante. Rio de Janeiro: Paz e Terra, 1977. p. 9-22.

LOBÃO, Jocimara S. B. et al. Aplicação de técnicas de geoprocessamento para mapeamento geomorfológico do polo de Guanambi: subsídios para o estudo da degradação ambiental e desertificação. REVISTA GEONORTE, Edição Especial, v. 2, n. 4, p. 173-186, 2012.

Lobão, Jocimara Souza Britto et al. Semiárido da Bahia, limites fisicos ou sócio-político: uma abordagem geotecnológica para delimitação oficial. In: SIMPÓSIO REGIONAL DE GEOPROCESSAMENTO E SENSORIAMENTO REMOTO, 11., 2004, Aracaju. Anais eletrônicos [...]. Aracajú, SE: UECE, 2011. Disponivel em: http://www. cpatc.embrapa.br/labgeo/srgsr2/pdfs/poster15.pdf. Acesso em: 01 abr. 2014. p. 1-4.

MAB - MOVIMENTO DOS ATINGIDOS POR BARRAGENS. Na Bahia, atingidos por barragens, marcham na BR 210. São Paulo, 10 fev. 2010. Disponivel em: http://www. mabnacional.org.br/noticia/na-bahia-atingidos-por-barragens-marcham-na-br-210. Acesso em: 26 de mar. 2020.

OLIVEIRA, Cláudio D.; ROCHA, Marina. Estudo de Caso Areia Grande: Resistir para existir. A luta no sertão baiano é pelo Fundo de Pasto! In: Movimento Regional Porlatierra, 22 fev. 2018. Disponivel em: https://www. porlatierra.org/docs/b26b492fo8dg6f7c25b4774cfe442fbe.pdf. Acesso em: 23 abr. 2020.
POLICIAMILITAR DA BAHIA. Histórico. Disponivel: http:// www.pm.ba.gov.br/index.php?option=com_content\&view=category\&id=94\&ltemid=547. Acesso em: 21 jul. 2020 .

PYL. Bianca. Ação direta de juiz acua comunidades de fundo de pasto. 2010. Reporter Brasil, São Paulo. 16 abr. 2009. Disponivel em: http://reporterbrasil.org. br/2010/04/acao-direta-de-juiz-acua-comunidades-de-fundo-de-pasto/. Acesso em: 10 abr. 2020.

REIMBERG, Mauricio. Área em disputa no sertão é palco de morte de trabalhador rural. Reporter Brasil ${ }_{\perp}$ São Paulo, 10 fev. 2009. Disponivel em: http://reporterbrasil.org. br/2009/02/rea-em-disputa-no-sertao-e-palco-de-morte-de-trabalhador-rural/. Acesso em: 10 jan. 2020.

REIS, Angélica Santos. Fundos de Pasto baianos: um estudo sobre regularização fundiária. Dissertação (Mestrado em Ciências Sociais). Universidade Federal da Bahia - UFBA, 2010. 242 f. Salvador - BA.

REVISTAALUMEIA. Mineração: progresso ou destruição. Salvador: CPT, 2013.

SANTOS. Cirlene Jeane Santos e. Fundos de Pasto: Tecitura da resistência, rupturas e permanências no tempo-espaço desse modo de vida camponês. Tese (Doutorado em Geografia). 2010. 290 f. Universidade de São Paulo - USP, São Paulo - SP, 2010.

STHEINBECK, John. As vinhas da Ira. Rio de Janeiro: Bestbolso, 2008.

TORRES, Paulo Rosa. Terra e Territorialidade das Áreas de Fundo de Pastos no Semiárido baiano 1980-2011. Dissertação (Mestrado em Planejamento Territorial e Desenvolvimento Sustentável). Universidade Católica do Salvador - UCSAL. 2011. 134 f. Salvador - BA.

\section{Simone Conceição Soares Dias}

Doutoranda em História na Universidade do Vale do Rio dos Sinos (Unisinos), em São Leopoldo, RS, Brasil; professora da rede pública estadual em Monte Santo, BA, Brasil.

\section{Endereço para correspondência}

Simone Conceição Soares Dias

Av. Des. Sálvio Martins, 314

Centro, 48800000

Monte Santo, BA, Brasil 